\title{
IMPLEMENTASI ALGORITMA APRIORI UNTUK MENENTUKAN PERSEDIAAN SPARE PART COMPRESSOR
}

\author{
Laela Kurniawati ${ }^{1}$, Aldo Esa Kusuma ${ }^{2}$, Benti Dewansyah ${ }^{3}$ \\ ${ }^{123}$ Sistem Informasi STMIK Nusa Mandiri Jakarta \\ ${ }^{123}$ Jl. Damai No.8 Warung Jati Barat (Margasatwa), Pasar Minggu, \\ Jakarta Selatan, 12450 Indonesia

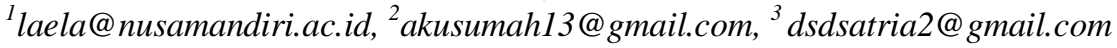

\begin{abstract}
Abstrak - Teknik Data mining banyak digunakan untuk mengatasi banyak permasalahan, salah satunya metode algoritma apriori yang digunakan untuk mendapatkan informasi tentang asosiasi antar produk dengan memanfaatkan database transaksi yang diolah akan menghasilkan aturan asosiasi keterkaitan yang kuat antar itemset, sehingga dapat memberi rekomendasi penyetokan barang serta mempermudah dalam penempatan itemset yang saling ketergantungan. PT. XYZ adalah perusahaan yang bergerak dibidang penjualan spare parts compressor. Dalam melakukan aktivitas bisnis perusahaan tidak mengetahui pasangan spare parts yang sering dibeli secara bersamaan. Saat stok spare parts yang jumlahnya tinggal sedikit, perusahaan hanya meminta kiriman stok spare parts tersebut tanpa mengetahui itemset spare parts yang dibeli secara bersamaan. Hal itu mempersulit penyetokan barang karena banyaknya jenis dari spare parts. Dengan algoritma apriori diharapkan dapat membantu perusahaan dalam menentukan persediaan itemset yang saling ketergantungan sehingga dari penentuan stock yang tepat akan mempermudah promosi supaya promosi yang dilakukan tepat sasaran.
\end{abstract}

Keywords — Data Mining, Algoritma Apriori, Persediaan Sper part

\section{PENDAHULUAN}

Seiring dengan perkembangan teknologi yang semakin pesat, saat ini pada umumnya perusahaan dan organisasi memanfaatkan database untuk menyimpan data transaksi perusahaan. Dari waktu kewaktu data yang tersimpan dalam database kuantitasnya semakin besar, kumpulan data yang besar tersebut jika diolah dengan menggunakan algoritma yang tepat maka akan menghasilkan informasi yang penting bagi perusahaan. Dengan mencari pola atau trend yang diinginkan pada database tersebut dapat membantu perusahaan dalam pengambilan keputusan diwaktu yang akan datang. Pencarian pola berdasarkan kumpulan data yang besar dikenal dengan istilah data mining.

Data mining dapat diterapkan dalam berbagai bidang salah satunya adalah bidang usaha perdagangan aktivitas penjualan. Dalam menjalankan aktivitas penjualan perusahaan harus dapat menentukan sasaran penjualan dengan baik agar penjualan yang dilakukan bisa dicapai dengan keuntungan yang maksimal, salah satu untuk memaksimalkan keuntungan pada penjualan bisa dilakukan dengan cara melakukan promosi produk yang dijual baik secara online maupun offline. Namun promosi yang dilakukan tersebut dinilai belum efektif karena ketika mempromosikan produk belum memperhitungkan seberapa besar kemungkinan pelanggan tertarik kepada produk tersebut [1], selain itu penentuan pembelian barang yang kurang akurat dapat mengakibatkan kebijakan rekomendasi produk dan promosi yang dilakukan tidak tepat sasaran [2]. Bila sasaran pelanggan tidak ditentukan dengan baik, maka hanya akan menghabiskan banyak waktu dan biaya [3]. Agar promosi yang dilakukan perusahaan tepat sasaran bisa dilakukan dengan memanfaatkan teknik data mining yaitu dengan menemukan pola-pola yang berasosiasi diantara produk-produk yang dipasarkan dan meningkatkan item-item produk yang berasosiasi tersebut, hal tersebut dapat dilakukan dengan cara mendeteksi kumpulan-kumpulan atribut yang muncul bersamaan yang dapat dilakukan dengan menggunakan teknik asosiasi dengan algoritma apriori.

PT. XYZ merupakan perusahaan yang bergerak dalam bidang penjualan spare parts mesin, serta memberikan pelayanan berupa perawatan (service) untuk mesin yang dijual. Setiap transaksi penjualan barang dilakukan penginputan pada database secara langsung yang terhubung dengan kantor pusat. Permasalahan yang saat ini dihadapi adalah dalam menentukan promosi spare part PT. XYZ tidak mengetahui pola pelanggan dalam membeli spare part mana yang dibeli secara bersamaan. Hal ini menyebabkan saat stok spare parts yang jumlahnya tinggal sedikit, kantor hanya meminta kiriman stok spare parts tersebut dari kantor pusat tanpa mengetahui spare parts yang lain yang jika spare parts tersebut dibeli maka spare parts yang lain juga dibeli. Hal itu dinilai mempersulit saat penyetokan barang karena banyaknya jenis dari spare parts tersebut. Teknik Data mining telah banyak digunakan untuk mengatasi permasalahan yang ada salah satunya dengan penerapan algoritma apriori untuk mendapatkan informasi tentang asosiasi antar produk dari suatu database transaksi. Data transaksi penjualan spare parts dapat diolah kembali menggunakan teknik data mining, sehingga menghasilkan aturan asosiasi 
keterkaitan yang kuat antar itemset pada penjualan spare parts kemudian bisa memberi rekomendasi penyetokan barang dan mempermudah dalam penataan atau penempatan barang yang memiliki ketergantungan yang kuat.

Page $\mid 7$

\section{LANDASAN TEORI}

\section{A. Data Mining}

Data Mining adalah proses yang memperkerjakan satu atau lebih teknik pembelajaran komputer (machime learning) untuk menganalisa dan mengekstrasi pengetahuan (knowledge) secara otomatis [4]. Salah satu teknik dalam data mining adalah teknik asosiasi. Tugas asosiasi dalam data mining adalah menemukan attribut yang muncul dalam satu waktu [5]. Analisis asosiasi atau association rule mining adalah teknik data mining untuk menemukan aturan asosiasi antara kombinasi item

\section{B. Algoritma Apriori}

Algoritma apriori adalah algoritma pengambilan data dengan aturan asosiatif (Association rule) untuk menentukan hubungan asosiatif suatu kombinasi item [4]. Ada dua pengukuran penting untuk sebuah rule yaitu support dan confidence [6]. Support adalah suatu ukuran yang menunjukkan seberapa besar tingkat dominasi suatu item atau itemset dari keseluruhan transaksi [7], untuk menghitung support 1 item set bisa menggunakan persamaan sebagai berikut [4]:

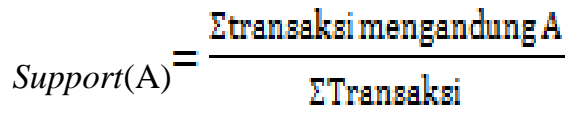

Untuk menghitung support 2 item set dapat diselesaikan dengan persamaan berikut [4]:

$$
\begin{aligned}
& \text { Support }(\mathrm{A}, \mathrm{B})=\mathrm{P}(\mathrm{A} \cap \mathrm{B}) \\
& \quad \text { Support }(\mathrm{A}, \mathrm{B}) \\
& \operatorname{Support}(\mathrm{A}, \mathrm{B})=\frac{\text { Itransaksi mengandung } \mathrm{A} \text { dan } \mathrm{B}}{\text { ETransalksi }}
\end{aligned}
$$

Untuk menghitung support 3 item set dapat diselesaikan dengan rumus berikut [4]:

$$
\begin{aligned}
& \text { Support }(A, B)=\frac{\text { Etransaksi mengandung } A, B, d a n C}{\text { stransaksi }} \\
& \text { Confidence adalah suatu ukuran yang } \\
& \text { confidence }=P(B \mid A)=\frac{\text { Etransaksi mengandung } A \text { dan } \mathrm{B}}{\text { Transaksi Mengandung } \mathrm{A}}
\end{aligned}
$$

\section{METODE PENELITIAN}

\section{A. Metode Pengumpulan Data}

Metode pengumpulan data yang digunakan pada penelitian ini yaitu studi lapangan dan studi pustaka. Studi lapangan digunakan untuk mengetahui seberapa jauh kesesuaian antara teori yang digunakan dengan keadaan yang sebenarnya dari objek yang diteliti, studi lapangan dilakukan dengan cara observasi atau penelitian langsung pada object penelitian dan mengumpulkan data - data yang diperoleh dan kemudian data tersebut akan diproses dengan menggunaka algoritma teknik data mining yaitu algoritma apriori, setelah dilakukan proses pengolahan data kemudian hasil dari pengolahan data tersebut akan dianalisa. Studi pustaka dilakukan untuk memahami penerapan data mining seperti teori-teori yang berhubungan dengan data mining dan metode algoritma apriori yang dilakukan dengan cara mempelajarinya melaluai berbagai macam sumber referensi seperti buku-buku, jurnal-jurnal dan internet. Studi lapangan

\section{B. Kerangka Penelitian}

Kerangka Penelitian yang dilakukan terdiri dari beberapa tahapan yaitu (1) Perumusan dan identifikasi masalah (2) Studi awal yaitu melakukan studi lapangan dan studi pustaka (3) Pengumpulan data (4) Pengolahan data (5) Hasil Penelitian (5) Kesimpulan. Kerangka penelitian tersebut dapat dilihat pada gambar 1.

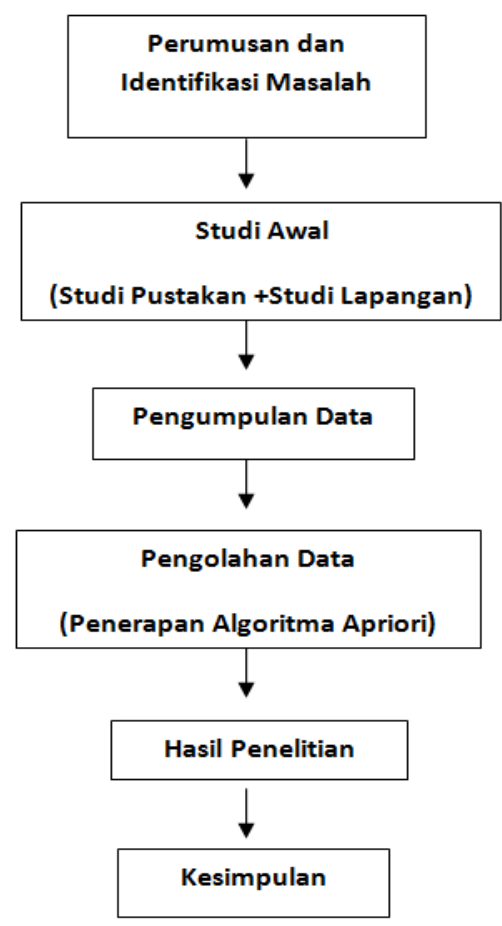

Gbr1. Kerangka Penelitian 


\section{HASIL DAN PEMBAHASAN}

\section{A. Pengolaha Data Transaksi}

Pada tahap pengolahan data transaksi data transaksi penjualan yang akan diproses adalah transaksi pada tahun 2017, akumulasi transaksi penjualan produk

Page $\mid 8$ diperoleh dari penjualan bulanan yang diambil dari penjualan teratas berdasarkan laporan bulanan, data transaksi yang digunakan bisa dilihat pada tabel 1 .

TABEL I

TRANSAKSI PENJUALAN SPARE PARTS

\begin{tabular}{|c|c|}
\hline Transaksi & Item Pembelian \\
\hline 1 & $\begin{array}{l}\text { Packing, Filter, Coil Ignition, } \\
\text { Retaining Ring, Shim }\end{array}$ \\
\hline 2 & $\begin{array}{l}\text { Ring Piston, O-Ring, Gasket, } \\
\text { Retaining Ring }\end{array}$ \\
\hline 3 & $\begin{array}{l}\text { Coil Ignition, Filter, Gasket, O-Ring, } \\
\text { Piston Seal }\end{array}$ \\
\hline 4 & Filter, Piston seal, Coil Ignition \\
\hline 5 & $\begin{array}{l}\text { Ring Piston, Filter, Retaining Ring, } \\
\text { Coil Ignition }\end{array}$ \\
\hline 6 & $\begin{array}{l}\text { O-Ring, Ring Piston, Gasket, } \\
\text { Coupling }\end{array}$ \\
\hline 7 & $\begin{array}{l}\text { Coupling, Coil Ignition, Retaining } \\
\text { Ring }\end{array}$ \\
\hline 8 & Packing, Filter, Piston Seal, Gasket \\
\hline 9 & $\begin{array}{l}\text { O-Ring, Ring Piston, Gasket, } \\
\text { Retaining Ring }\end{array}$ \\
\hline 10 & Coil Ignition, Piston Seal, Filter \\
\hline 11 & $\begin{array}{l}\text { Filter, Packing, Gasket, O-Ring, } \\
\text { Piston Seal }\end{array}$ \\
\hline 12 & $\begin{array}{l}\text { Ring Piston, Gasket, O-Ring, } \\
\text { Retaining Ring }\end{array}$ \\
\hline 13 & $\begin{array}{l}\text { Ring Piston, Coil Ignition, O-Ring, } \\
\text { Filter }\end{array}$ \\
\hline 14 & $\begin{array}{l}\text { Packing, Filter, Coil Ignition, } \\
\text { Coupling, Gasket }\end{array}$ \\
\hline 15 & $\begin{array}{l}\text { Ring Piston, O-Ring, Filter, } \\
\text { Retaining Ring }\end{array}$ \\
\hline 16 & Filter, Coil Ignition, Gasket, Spring \\
\hline 17 & $\begin{array}{l}\text { Coupling, Coil Ignition, Piston Seal, } \\
\text { Packing }\end{array}$ \\
\hline 18 & $\begin{array}{l}\text { Piston Seal, Filter, Gasket, Coil } \\
\text { Ignition, Packing }\end{array}$ \\
\hline 19 & Retaining Ring, Ring Piston, O-Ring \\
\hline 20 & $\begin{array}{l}\text { Packing, Coil Ignition, Gasket, } \\
\text { Retaining Ring }\end{array}$ \\
\hline
\end{tabular}

Berdasarkan sampel data pada tabel 1 peneliti membuat kode-kode item untuk setiap barang yang dijadikan sample untuk mempermudah proses pengolahan data selanjutnya, kode-kode item masingmasing barang bisa dilihat pada tabel 2 .
TABEL II

KODE-KODE MASING-MASING ITEM

\begin{tabular}{|c|c|}
\hline $\begin{array}{l}\text { Kode } \\
\text { Item }\end{array}$ & Nama Spare parts \\
\hline S01 & Coil Ignition \\
\hline S02 & Coupling \\
\hline S03 & Filter \\
\hline S04 & Gasket \\
\hline S05 & O-Ring \\
\hline S06 & Packing \\
\hline S07 & Piston Seal \\
\hline S08 & Retaining Ring \\
\hline S09 & Ring Piston \\
\hline S10 & Shim \\
\hline S11 & Spring \\
\hline
\end{tabular}

\section{B. Membuat Representasi Biner}

Untuk mempermudah dalam analisa asosiasi, peneliti membuat sebuah tabel representasi biner untuk setiap transaksi yang dilakukan. Nilai atribut dinyatakan 1 jika pada transaksi tersebut terdapat pembelian untuk barang yang dimaksud, nilai atribut dinyatakan "0" jika dalam transaksi tersebut tidak ada penjualan untuk barang yang dimaksud. Berdasarkan rincian transaksi pada tabel 1 maka refresentasi biner yang dihasilkan bisa dilihat pada tabel 3 sebagai berikut:

TABEL III

REFRESENTASI BINER TRANSAKSI PENJUALAN SPARE

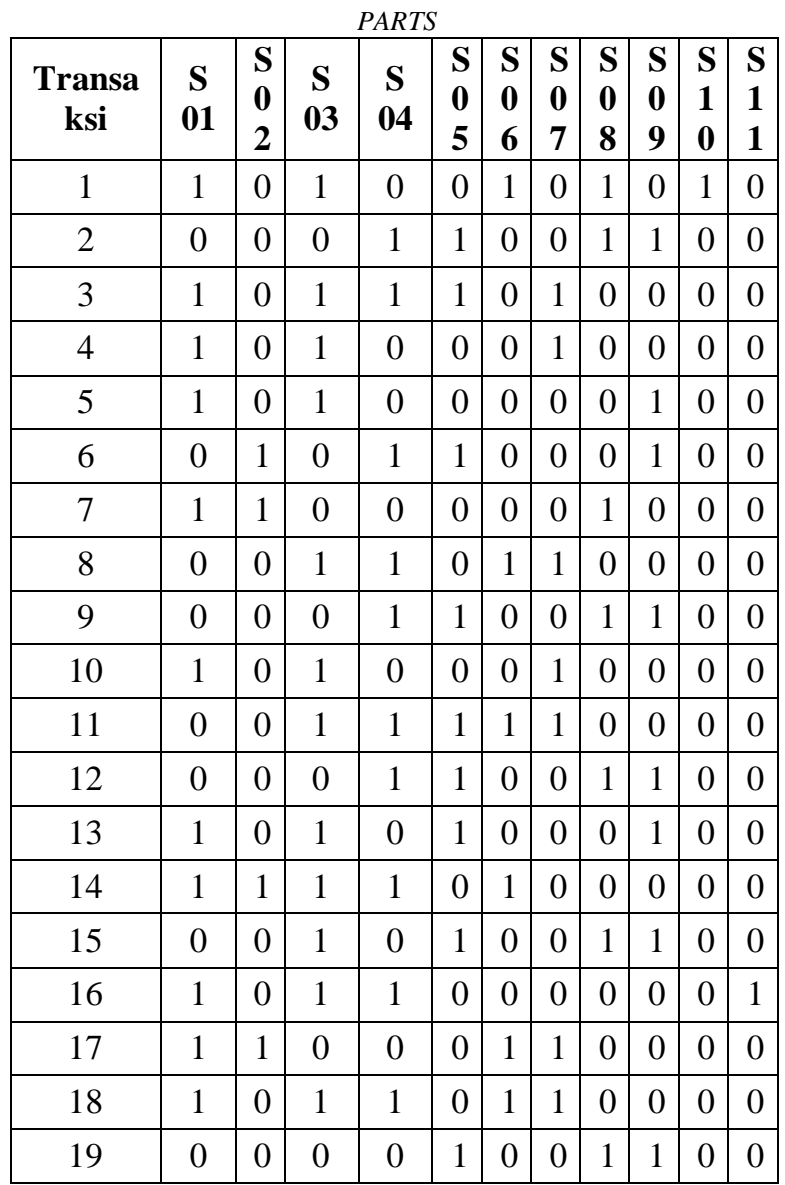




\begin{tabular}{|c|c|c|c|c|c|c|c|c|c|c|c|}
\hline 20 & 1 & 0 & 0 & 1 & 0 & 1 & 0 & 1 & 0 & 0 & 0 \\
\hline Jumlah & 12 & 4 & 12 & 11 & 9 & 7 & 7 & 9 & 9 & 1 & 1 \\
\hline
\end{tabular}

\section{Menentukan Support Dan Confidence}

Berdasarkan data yang sudah disediakan pada tabel

Page| 93 kemudian proses pembentukan $\mathrm{C} 1$ atau disebut dengan 1 itemset dengan jumlah minimum support $=$ $40 \%$, untuk menghitung support 1 item set bisa menggunakan persamaan sebagai berikut:

$$
\operatorname{Support}(\mathrm{A})=\frac{\text { EtransaksimengandungA }}{\text { ETransaksi }}
$$

Hasil dari pembentukan 1 item set dapat dilihat pada tabel 4.

TABEL IV

SUPPORT DARI SETIAP ITEM

\begin{tabular}{|c|c|c|}
\hline $\begin{array}{c}\text { Kode_Spare } \\
\text { parts }\end{array}$ & Jumlah & Support \\
\hline S01 & 12 & $60 \%$ \\
\hline S02 & 4 & $20 \%$ \\
\hline S03 & 12 & $60 \%$ \\
\hline S04 & 11 & $55 \%$ \\
\hline S05 & 9 & $45 \%$ \\
\hline S06 & 7 & $35 \%$ \\
\hline S07 & 7 & $35 \%$ \\
\hline S08 & 9 & $45 \%$ \\
\hline S09 & 9 & $45 \%$ \\
\hline S10 & 1 & $5 \%$ \\
\hline S11 & 1 & $5 \%$ \\
\hline
\end{tabular}

Dari proses pembentukan 1 itemset pada tabel 3 dengan minimum support $40 \%$ dapat diketahui yang memenuhi standar minimum support yaitu pada spare parts S01, S03, S04, S05, S08, S09. Kemudian dari hasil pembentukan 1 itemset akan dilakukan kombinasi 2 itemset, pembentukan 2 item set tidak dilakukan pada semua jenis spare parts, tetapi hanya pada spare parts yang memiliki support lebih besar dari minimum support.

Proses selanjutnya adalah pembentukan C2 atau disebut dengan 2 itemset dengan jumlah minimum support $=40 \%$. Untuk menghitung support 2 item set dapat diselesaikan dengan persamaan berikut:

$$
\begin{aligned}
& \text { Support }(\mathrm{A}, \mathrm{B})=\mathrm{P}(\mathrm{A} \cap \mathrm{B}) \\
& \quad \operatorname{Support}(\mathrm{A}, \mathrm{B}) \\
& \operatorname{Support}(\mathrm{A}, \mathrm{B})=\frac{\text { 2transaksi mengandung } \mathrm{A} \text { dan } \mathrm{B}}{\text { ETransalkil }}
\end{aligned}
$$

TABEL V

MINIMUM SUPPORT 2 ITEM SET

\begin{tabular}{|c|c|c|}
\hline Kode_Spare parts & Jumlah & Support \\
\hline S01, S03 & 9 & $45 \%$ \\
\hline S01, S04 & 5 & $30 \%$ \\
\hline S01, S05 & 2 & $10 \%$ \\
\hline S01, S08 & 4 & $20 \%$ \\
\hline S01, S09 & 3 & $10 \%$ \\
\hline S03, S04 & 6 & $30 \%$ \\
\hline S03, S05 & 4 & $15 \%$ \\
\hline S03, S08 & 4 & $15 \%$ \\
\hline S03, S09 & 4 & $15 \%$ \\
\hline S04, S05 & 6 & $30 \%$ \\
\hline S04, S08 & 5 & $25 \%$ \\
\hline S04, S09 & 4 & $20 \%$ \\
\hline S05, S08 & 6 & $30 \%$ \\
\hline S05, S09 & 7 & $35 \%$ \\
\hline S08, S09 & 5 & $25 \%$ \\
\hline
\end{tabular}

Dari kombinasi 2 itemset dengan minimum support $40 \%$ dapat diketahui kombinasi 2 itemset yang memenuhi standar minimum support yaitu Coil Ignition, Filter dengan support sebesar $45 \%$ dan ORing, Ring Piston dengan support $40 \%$. Dari hasil kombinasi 2 itemset untuk 2 item set yang memenuhi minimum support akan dilakukan pembentukan 3 itemset seperti pada tabel 5 .

Proses pembentukan C3 atau disebut dengan 3 itemset dengan jumlah minimum support $=40 \%$ Dapat diselesaikan dengan rumus berikut:

$$
\text { Support }(\mathrm{A}, \mathrm{B})=\frac{\text { atransaksi mengandung } \mathrm{A}_{1} \mathrm{~B}_{\mathrm{dan}} \mathrm{C}}{\text { transaksi }}
$$

TABEL VI

MINIMUM SUPPORT 3 ITEM

\begin{tabular}{|c|c|c|}
\hline Kode_Spare parts & Jumlah & Support \\
\hline S01, S03, S05 & $\mathbf{2}$ & $10 \%$ \\
\hline S01, S03, S09 & $\mathbf{2}$ & $10 \%$ \\
\hline S01, S05, S09 & $\mathbf{2}$ & $10 \%$ \\
\hline S03, S05, S09 & $\mathbf{3}$ & $15 \%$ \\
\hline
\end{tabular}

Berdasarkan tabel 6, kombinasi 3 itemset tidak ada yang memenuhi minimal support $40 \%$, maka kombinasi 2 itemset yang memenuhi untuk pembentukan asosiasi.

Setelah semua pola frekuensi tinggi ditemukan, barulah dicari aturan asosiasi yang 
memenuhi syarat minimum untuk confidence dengan menghitung confidence aturan asosiatif $\mathrm{A} \rightarrow \mathrm{B}$.

Minimum Confidence $=70 \%$

Nilai Confidence dari aturan $\mathrm{A} \rightarrow \mathrm{B}$ diperoleh dengan persamaan dibawah ini

Page $\mid 10$

$$
\text { confidence }=P(B \mid A)=\frac{\text { Etransaksi mengandung } A \text { dan } B}{\text { 2Transaksi Mengandung } A}
$$

TABEL VII

MINIMUM CONFIDENCE 2 ITEM

\begin{tabular}{|l|l|l|}
\hline Aturan & \multicolumn{2}{|c|}{ Confidence } \\
\hline $\begin{array}{l}\text { Jika membeli S01 } \\
\text { maka membeli S03 }\end{array}$ & $9 / 12$ & $75 \%$ \\
\hline $\begin{array}{l}\text { Jika Membeli S05 } \\
\text { maka membeli S09 }\end{array}$ & $8 / 9$ & $88 \%$ \\
\hline
\end{tabular}

Berdasarkan Tabel 6, spare parts yang paling sering dibeli oleh konsumen adalah O-Ring, Ring Piston, Coil Ignition dan Filter dengan diketahuinya spare parts yang paling sering dibeli konsumen, maka perusahaan dapat menyusun strategi dalam penentuan pembelian spare parts untuk menjaga ketersedians spare parts yang dibutuhkan konsumen dan juga dapat mengatur tata letak Spare parts berdasarkan kombinasi itemset spare parts yang terbentuk.

\section{KESIMPULAN}

Berdasarkan hasil penelitian yang telah dilakukan dapat diambil kesimpulan: (1) Penerapan data mining dengan menggunakan teknik algoritma apriori cukup efektif membantu dalam proses penentuan persediaan spare part pada perusahaan, (2) Metode algoritma apriori dalam penentuan pola penjualan dapat dilakukan dengan melihat hasil dari kecenderungan konsumen dalam membeli spare parts, (3) Berdasarkan pola pembelian spare parts yang di olah dari data transaksi-transaksi sebelumnya, kombinasi 2 itemset menghasilkan spare part yang sering dibeli bersamaan dengan nilai support di atas nilai minimum support, (4) Sedangkan kombinasi 3 itemset tidak ada yang memenuhi minimal support sehingga tidak terbentuk asosiasi, (5) Berdasarkan kombinasi 2 itemset diketahui kombinasi 2 itemset yang memenuhi standar minimum support yaitu Coil Ignition, Filter dengan support sebesar $45 \%$ dan O-Ring, Ring Piston dengan support $40 \%$, (6) Berdasarkan perhitungan confidence dengan nilai minimum $70 \%$ maka Spare parts yang paling sering dibeli oleh konsumen adalah O-Ring, Ring Piston, Coil Ignition dan Filter.

\section{UCAPAN TERIMAKASIH}

Terimakasih kepada Iwan Sulistiono yang sudah banyak meluangkan waktu untuk membantu secara teknis dalam proses penelitian ini.

\section{REFERENSI}

[1] R. R. Rerung, "Penerapan Data Mining dengan Memanfaatkan Metode Association Rule untuk Promosi Produk," J. Teknol. Rekayasa, vol. 3, no. 1, Juni, pp. 89-98, 2018.

[2] W. A. Triyanto, "Association Rule Mining Untuk Penentuan Rekomendasi,” J. Simetrsis, vol. 5, no. 2, pp. 121-126, 2014.

[3] R. Yanto and R. Khoiriah, "Implementasi Data Mining dengan Metode Algoritma Apriori dalam Menentukan Pola Pembelian Obat," Citec J., vol. Vol. 2, No, no. Februari-April 2015, ISSN: 2354-5771, pp. 102-113, 2015.

[4] F. A. Hermawati, Data Mining, no. January 2013. Yogyakarta: ANDI, 2013.

[5] Y. D. Handarkho, "Implementasi Sistem Informasi Bank Sampah Pada Usaha Kecil Menengah (Studi Kasus Bank Sampah Gemah Ripah Badegan, Bantul," in Konferensi Nasional Ilmu Komputer, 2014, pp. 1-8.

[6] D. S. Kusumo, M. A. Bijaksana, and D. Darmantoro, "Data Mining Dengan Algoritma Apriori Pada RDBMS Oracle," $J$. Penelit. dan Pengemb. Telekomun., vol. 8, no. 1, pp. 1-5.

[7] G. Gunadi and D. I. Sensuse, "Penerapan Metode Data Mining Market Basket Analysis Terhadap Data Penjualan Produk Buku Dengan Menggunakan Algoritma Apriori Dan Frequent Pattern Growth (FP-Growth): Studi Kasus Percetakan PT. Gramedia," J. Telemat. Mkom, vol. 4, no. 1, pp. 118-132, 2012. 